Check for updates

The BMJ

Cite this as: BMJ2020;369:m2526 http://dx.doi.org/10.1136/bmj.m2526 Published: 24 June 2020

\section{Covid-19: Prime minister announces relaxation of England's lockdown and social distancing rules}

\section{Abi Rimmer}

The prime minister, Boris Johnson, has announced a major relaxation of England's lockdown rules, including reducing social distancing from two metres to at least one metre "with precautions."

The new guidelines, effective from 4 July, will also allow restaurants and businesses to reopen and will permit separate households to meet indoors.

Announcing the changes in the Commons on 23 June, Johnson said that any future "flare-ups" of covid-19 would be dealt with locally but that the government would reintroduce restrictions at a national level if required. The government has also relaxed its guidance for people who have been shielding, so that from 6 July they will be able to spend time outdoors in a group of up to six people, while maintaining social distancing.

Johnson explained that restaurants and pubs that reopen from 4 July will be asked to collect customers' contact details to support the test and trace programme. Hairdressers, leisure facilities, and tourist attractions such as theme parks, museums, and galleries will also be permitted to reopen, as will places of worship. But close proximity venues such as indoor gyms, swimming pools, and nightclubs will remain closed.

Johnson added that all primary and secondary education would recommence in September.

\section{Face covering}

While people will continue to be advised to keep two metres apart, where this is not possible they will now be advised to maintain a distance of at least one metre while taking additional precautions such as wearing a face covering.

From 4 July two households of any size will be permitted to meet, inside or outside. But multiple households will still not be allowed to meet together indoors, and the guidance remains that a maximum of six people from different households can meet outside.

In response, the Labour leader, Keir Starmer, said, “There are obviously a number of questions that need to be answered, but overall I welcome this statement.” He asked Johnson whether the announcement had the support of the chief medical officer, chief scientific officer, and the Scientific Advisory Group for Emergencies (SAGE). Johnson responded that the chief medical and scientific officers had been involved in developing the new approach, but he did not mention SAGE.

In guidance published on 4 June SAGE's Environmental and Modelling Group recommended that people should continue to observe a distance of two metres when meeting face to face. It said that the best current evidence suggested that social distancing of one metre "carries between 2 and 10 times the risk of two metres of separation." 1

\section{Science and evidence}

Susan Michie, a member of the SAGE scientific pandemic influenza group on behaviours, said that the prime minister seemed to be circumventing SAGE and handpicking evidence to support his desired policy.

“This is 'science following policy'-rather than the other way round-when the science doesn't suit," she said. "To evaluate the wisdom and likely consequences of the changes, all the relevant SAGE evidence and advice should be published along with that of the Downing Street experts.”

Independent SAGE, a separate group set up and chaired by former the chief scientific adviser David King, also called for the government to release the evidence on which it had based its decision.

"Independent SAGE has done its own review of the available evidence, and we agree with SAGE's conclusion," said King. "The rate of infection is still far too high to consider this, even with mitigating measures."

Jackie Applebee, a Tower Hamlets GP, said she was concerned that the changes would give the false impression that the threat of covid-19 had gone away.

She said, "To suppress the virus properly, the government needs to invest in locally run community contact tracing systems, devolving the organisation to local public health teams who have the specific knowledge of their areas to gain the trust of people asked to isolate and to tailor support to local needs.”

Azeem Majeed, professor of public health at Imperial College London, welcomed the easing of the lockdown and shielding restrictions but said that people needed to remain vigilant, continue to practise good hygiene, avoid large crowds of people, and wear face masks. 
He added, "We also need the government to do its part by ensuring that its testing and tracing service is fully functional and [by] working effectively with local public health and NHS teams, so that any local outbreaks can be identified promptly and quickly suppressed.”

Correction: On 24 June 2020 we amended this article to make clear that the rule changes applied to England, not the UK.

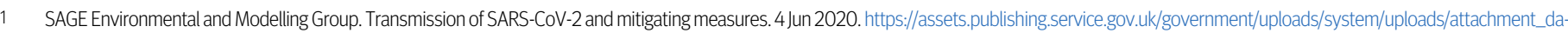
ta/file/892043/S0484_Transmission_of_SARS-CoV-2_and_Mitigating_Measures.pdf.

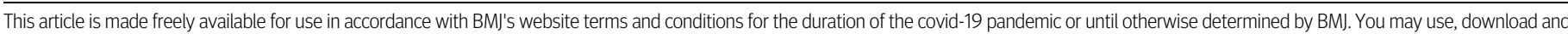
print the article for any lawful, non-commercial purpose (including text and data mining) provided that all copyright notices and trade marks are retained. 